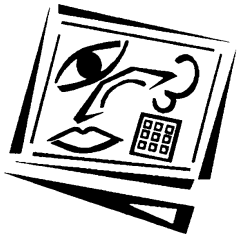

\title{
Rochester Castle MMORPG: Instructional gaming and collaborative learning at a Western Australian school
}

Mark J.W. Lee

Macquarie University

Ken Eustace, Geoff Fellows, Allan Bytheway

Charles Sturt University

Leah Irving

Deakin University

This paper reports on the first stage of a project to develop and test the use of massively multiplayer online role playing games (MMORPGs) for promoting computer supported collaborative learning through instructional gaming in the high school classroom. Teachers and students of English and Science at Swan View Senior High School, Western Australia were involved in a pilot study as "proof of concept", in which they participated in both game design and game play within a $\mathrm{MOO}$ based collaborative virtual environment with a medieval castle theme.

\section{Introduction}

The authors believe that the overlap between computer supported collaborative learning (CSCL), play theory and games design theory can be applied to K-12 teaching practice. Specifically, they believe that massivelymultiplayer online role playing games (MMORPGs) are especially effective to this end. In a MMORPG, large numbers of players - often to the order of thousands or even tens of thousands - form groups, clans or guilds to take up role play together in a dynamic, online virtual world. Publicly available and commercial MMORPGs such as Meridian 59, Ultima Online, Utopia, EverQuest, Final Fantasy XI, Guild Wars and Dark Age of Camelot have large fan bases spanning all age groups, and there is much evidence of learning that takes place in the immersive worlds created by these games.

The Research into Professional Practice, Learning and Education (RIPPLE) research centre at Charles Sturt University funded a project involving the 
development, testing and investigation of the use of educational MMORPGs, based on the authors' existing work with computer supported collaborative learning and virtual learning environments. The research team was formed within the Internet Special Projects Group (ISPG) at Charles Sturt University after an approach by Leah Irving from Deakin University to study the application of MMORPGs to classes at Swan View Senior High School, Western Australia, with the assistance of teacher Dianne Hobbs and Technology Coordinator, Mark Weber.

Rieber (1996) proposed a hybrid learning environment in which the constructivist concept of a microworld was supported with simulation and gaming characteristics. The authors take this further by proposing:

1. that massively multiplayer online role playing games (MMORPGs) can be used for developing social and emotional skills that can then be applied in real life (Irving, 2004); and

2. that instructional gaming which combines collaborative learning and game design theories can be part of the professional practice of many educators. (Many educators often wonder if the instructional gaming is worth the effort required by teachers and students).

This paper reports on the design, implementation and use of a MMORPG for a pilot study culminating in the findings of the first stage of the project. The pilot study involved developing a "proof of concept" involving Year 8 and 9 English and Science classes at Swan View Senior High School, studying topics related to medieval times.

\section{Literature review}

Play theory is based largely around the observation that like other animals, humans learn more through the games they play in their early years than they do in any other corresponding time in their lives (Van Eck, 2000, citing Lepper \& Chabay, 1985). This idea is echoed by Piaget (1951), who called play "the work of a child", as well as Rieber (1996), according to whom "play is an important mediator for learning and sociali[s]ation throughout life" (p.44), and who also contends that "[h]aving children play games to learn is simply asking them to do what comes naturally" (p.52).

Similarly, Stewart Butterfield, CEO of Ludicorp, developer of the Game Neverending, expressed the following view:

We play all the time, even when there is nothing like a formal game going on - think of great conversations and all the verbal play, of "goofing around", of flirting, of musicians jamming: these are all moments where the creativity is 
flowing, you feel completely alive, and you are able to fully express yourself at the peak of your ability without even trying. (Butterfield, 2003)

(The Game Neverending is a MMORPG which incorporates many of the social elements of MOOs, a concept that served as a major source of inspiration and ideas for the project.)

Computer games represent one form of play. Many recent books, such as those authored by Marc Prensky (2001), Clark Aldrich (2004) and James Paul Gee (2003), highlight the educational and cognitive benefits of learning through computer and video games and simulations. Gee (2004) alludes to the increasing pervasiveness of computer and video games in modern society:

...[they] are going to become the predominate form of popular culture

interaction in our society...their power and complexity...[will] make a better and smarter society. (Introduction section, para. 6)

In particular, today's youth, who Prensky (2001) calls the "digital natives" have modern information and communications technologies (ICTs), including computer games and the Internet, finely ingrained into their culture:

The Games Generation has been raised with, and become accustomed to, the worldwide connectedness of email, broadcast messages, bulletin boards, user groups, chat, multiplayer games, and instant messaging (Prensky, 2001: 57).

According to the Game Developers' Association of Australia (2003), the Australian interactive entertainment industry reported a combined sales figure of $\$ 825$ million in 2002. Australians are spending $\$ 2.3$ million per day on interactive games, approximately equal to their expenditure on movies. In the twelve months to April 2003, more than $71 \%$ of children in Australia played electronic or computer games outside school hours during a school term (Australian Bureau of Statistics, 2003). Boys and girls spent an average of 9 hours and 5.3 hours per week respectively playing such games.

According to Papert (1998), kids dislike school because it is boring; not because it is hard. Games, on the other hand, can be "hard fun" and enjoyable due to their complexity. Instead of reacting negatively towards computer games, teachers and schools should leverage the technologies students already play with, to enhance their learning experiences.

Successful computer game players master a variety of skills and knowledge in the course of game play. Gee (2004) suggests that what makes the games themselves deep is actually the learning players engage in, though this is often done subconsciously or even unconsciously. As such, he claims that good game designers use methods similar in many respects to principles 
being discovered in recent research on human learning. He further proposes that many "non-educational", commercial, off the shelf, (COTS) games exhibit the use of techniques that demonstrate sound learning principles - to an even greater degree than most so called "educational" games. Instructional game designers therefore have much to learn from an examination of these COTS games.

One of the four most important aspects of cognitive psychology as it relates to instructional game design is affect (Thurman, 1993). The rich media and multiple representations of games and computer based instruction (CBI) in general can boost affect and motivation (Van Eck, 2000, citing Hannafin \& Peck, 1988). Furthermore, in a well-designed game, players learn because they need to in order to play the game - motivation is built into the game itself. Lepper and Malone (1987) identify seven theories of "intrinsic motivation" to guide the processes involved in game design:
1. Challenge;
2. Curiosity;
3. Control;
4. Fantasy;
5. Competition;
6. Cooperation;
7. Recognition.

The last three elements of intrinsic motivation were categorised as "interpersonal motivation". These three theories are of particular interest in the application of MMORPGs to collaborative learning and teaching practice in schools. Collaborative learning (CL), has its roots in the work of Piaget (1951) and Vygotsky (1978) and is based on the view that learners learn best through positive, cooperative interactions with one another. Computer supported collaborative learning (CSCL) focuses on the use of information and communication technologies (ICTs) as a mediating tool for collaborative virtual environments (CVEs), and as such can serve as a theoretical paradigm for online role playing games to support learning. Founded in social constructivism, CL and CSCL emphasise an understanding of language, culture and the social setting. They are especially worthwhile where problem solving or project based learning is concerned (Johnson \& Johnson, 1999; Johnson, Johnson \& Stanne, 2004) with achieving a common group goal. A MMORPG by its nature, is both problem based and project based in learning.

Closely related to these issues are the positive effects that the social phenomenon of community can have on learning and knowledge construction, as highlighted by the work of Dewey (1929), Vygotsky (1978), Bruner (1986, 1990, 1996), Kafai \& Resnick (1996) and Cunningham (1996). Modern ICT technologies can be put to use in the development of learning 
communities in an online context (Bonk \& Wisher, 2000; Hiltz, 1998; Palloff \& Pratt, 1999). Online gaming communities such as MMORPGs are excellent examples of this as, as new players are immersed into the sociocultural practices of the community and master new knowledge and skills through their interactions with others:

[The] Game Neverending...[is] not really a game at all. It's a social space designed to facilitate and enable play. The game-elements are there to provide both the constraints and the building blocks of interaction - since [this] kind of play...is the kind of thing that goes on between people.

(Butterfield, 2003)

There are concerns about many computer and video games because of their emphasis on violent, sexual or criminal activities, as well as the monetary and time costs of playing, particularly in commercial, "pay to play" gaming environments. On the plus side, participant interaction in cooperatively designing, building and using a MMORPG affords specific cognitive advantages to student learning. Rieber (1996) says "playing a game successfully can require extensive critical thinking and problem-solving skills". In fact, according to Gikas \& Van Eck (2004), role playing games such as MMORPGs effectively map across to all five of Gagné's intellectual skills, and all six levels of Bloom's taxonomy of the cognitive domain (Table 1). This is done by immersing players in the intricacies of the characters, story, combat and the virtual world in which the game is set. This is not always the case with educational or "edutainment" games, which are typically designed to teach a specific body of knowledge in line with a set of defined goals.

Typical gaming communities or guilds display a pattern of cooperative problem solving behaviour, as seen in a study of online gaming communities named Project Massive (2004). Players quickly realise that the

Table 1: Mapping of a game taxonomy against two learning taxonomies (adapted from Gikas \& Van Eck, 2004).

\begin{tabular}{|c|c|c|c|c|c|c|c|c|c|c|c|c|c|}
\hline \multirow[b]{2}{*}{$\begin{array}{l}\text { Bates' } \\
\text { taxon- } \\
\text { omy of } \\
\text { games }\end{array}$} & \multirow[b]{2}{*}{ Explanation of genre } & \multicolumn{5}{|c|}{$\begin{array}{c}\text { Gagné's } \\
\text { intellectual } \\
\text { skills }\end{array}$} & \multicolumn{7}{|c|}{$\begin{array}{l}\text { Bloom's } \\
\text { taxonomy }\end{array}$} \\
\hline & & 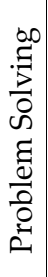 & 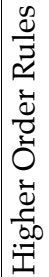 & 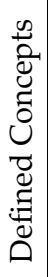 & 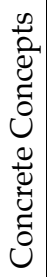 & 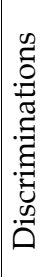 & $\frac{\sqrt{7}}{3}$ & क & $\frac{\frac{0}{5}}{\frac{1}{2}}$ & & & & $\begin{array}{l}0 \\
\frac{0}{0} \\
\frac{0}{3} \\
0 \\
\frac{1}{2}\end{array}$ \\
\hline
\end{tabular}




\begin{tabular}{|c|c|c|c|c|c|c|c|c|c|c|c|c|}
\hline Action & $\begin{array}{l}\text { Keep the player moving and involved } \\
\text { at all times. Primary skills are } \\
\text { eye/hand coordination and quick } \\
\text { reflexes. Deep thinking is generally not } \\
\text { required. } \\
\text { COTS examples: Dark Age of Camelot, } \\
\text { Jedi Knight, Medal of Honor, Halo, } \\
\text { Doom, Half Life, Duke Nukem, Unreal } \\
\text { Tournament, Quake, Deux Ex: } \\
\text { Invisible War, Star Wars: Battlefront, } \\
\text { Star Wars: Republic Commando }\end{array}$ & & & $\sqrt{ }$ & $\sqrt{ }$ & $\sqrt{ }$ & & & & $\sqrt{ }$ & $\sqrt{ }$ & $\sqrt{ }$ \\
\hline $\begin{array}{c}\text { Role } \\
\text { playing }\end{array}$ & $\begin{array}{l}\text { Revolves around characters, story and } \\
\text { combat and takes place in large, } \\
\text { expansive worlds and played out over } \\
\text { hundreds of hours. } \\
\text { COTS examples: Baldur's Gate, Diablo, } \\
\text { Icewind Dale, Neverwinter Nights, } \\
\text { Ultima Online, EverQuest, Star Wars } \\
\text { Galaxies, Final Fantasy }\end{array}$ & $\sqrt{ }$ & $\sqrt{ }$ & $\sqrt{ }$ & $\sqrt{ }$ & $\sqrt{ }$ & $\sqrt{ }$ & $\sqrt{ }$ & $\sqrt{ }$ & $\sqrt{ }$ & $\sqrt{ }$ & $\sqrt{ }$ \\
\hline $\begin{array}{l}\text { Adven- } \\
\text { ture }\end{array}$ & $\begin{array}{l}\text { Story based on exploration and puzzle } \\
\text { solving where the player is the hero. } \\
\text { Examples: CSI, Law \& Order, Dragon's } \\
\text { Lair 3D, Myst, Beyond Atlantis, } \\
\text { Leisure Suit Larry, Syberia, Freddi } \\
\text { Fish, Pajama Sam }\end{array}$ & $\sqrt{ }$ & $\sqrt{ }$ & $\sqrt{ }$ & $\sqrt{ }$ & $\sqrt{ }$ & $\sqrt{ }$ & $\sqrt{ }$ & $\sqrt{ }$ & $\sqrt{ }$ & $\sqrt{ }$ & $\sqrt{ }$ \\
\hline Strategy & $\begin{array}{l}\text { Effective strategy games are balanced. } \\
\text { Just enough information is provided } \\
\text { for motivation and interest. Too much } \\
\text { information, the player doesn't make } \\
\text { effective decisions; too little } \\
\text { information the player spends time } \\
\text { worrying about what to exclude. } \\
\text { COTS examples: Rise of Nations, } \\
\text { Civilization, Capitalism, Age of } \\
\text { Empires, Command \& Conquer, } \\
\text { Warcraft, Starcraft, Black \& White, } \\
\text { Battle Realms, Lord of the Rings: The } \\
\text { Battle for Middle Earth }\end{array}$ & $\sqrt{ }$ & $\sqrt{ }$ & $\sqrt{ }$ & $\sqrt{ }$ & $\sqrt{ }$ & $\sqrt{ }$ & $\sqrt{ }$ & $\sqrt{ }$ & $\sqrt{ }$ & $\sqrt{ }$ & $\sqrt{ }$ \\
\hline $\begin{array}{l}\text { Simul- } \\
\text { ations }\end{array}$ & $\begin{array}{l}\text { The purest form of wish fulfillment; } \\
\text { fulfill the players' fantasies of what } \\
\text { they cannot do in real life. } \\
\text { COTS examples: The Sims, Sim City, } \\
\text { Cruise Ship Tycoon, Zoo Tycoon, } \\
\text { Rollercoaster Tycoon, Flight Simulator, } \\
\text { Train Simulator, Theme Hospital, } \\
\text { Championship Manager, Casino } \\
\text { Empire, LegoLand }\end{array}$ & $\sqrt{ }$ & $\sqrt{ }$ & $\sqrt{ }$ & $\sqrt{ }$ & $\sqrt{ }$ & $\sqrt{ }$ & $\sqrt{ }$ & $\sqrt{ }$ & $\sqrt{ }$ & $\sqrt{ }$ & $\sqrt{ }$ \\
\hline Sports & $\begin{array}{l}\text { Allows players to play their favorite } \\
\text { sports activity to their heart's content. } \\
\text { COTS examples: Tiger Woods PGA } \\
\text { Tour, NHL 2004, NBA Live 2005, } \\
\text { Nascar Racing }\end{array}$ & & & $\sqrt{ }$ & $\sqrt{ }$ & $\sqrt{ }$ & & & & $\sqrt{ }$ & $\sqrt{ }$ & $\sqrt{ }$ \\
\hline
\end{tabular}




\begin{tabular}{|c|c|c|c|c|c|c|c|c|c|c|c|c|}
\hline $\begin{array}{c}\text { Fighting } \\
\text { games }\end{array}$ & $\begin{array}{l}\text { Allows players to taunt their rival who } \\
\text { is playing beside them. Special moves } \\
\text { and signature moves are a must. } \\
\text { COTS examples: Mortal Kombat, } \\
\text { WWE Raw, Virtua Fighter, } \\
\text { CyberGladiators, X-Men: Children of } \\
\text { the Atom, Arthur's Knights: Tales of } \\
\text { Chivalry, Nightmare Creatures, } \\
\text { Akimbo: Kung-Fu Hero }\end{array}$ & & & $\sqrt{ }$ & $\sqrt{ }$ & $\sqrt{ }$ & & & & $\sqrt{ }$ & $\sqrt{ }$ & $\sqrt{ }$ \\
\hline Casual & $\begin{array}{l}\text { Games for the "new gamers" - easy to } \\
\text { learn and not difficult to master. } \\
\text { COTS examples: Who Wants to be a } \\
\text { Millionaire?, Monopoly, Chessmaster, } \\
\text { Pong, Risk II, Worms Blast }\end{array}$ & & & $\sqrt{ }$ & $\sqrt{ }$ & $\sqrt{ }$ & & & & $\sqrt{ }$ & $\sqrt{ }$ & $\sqrt{ }$ \\
\hline $\begin{array}{l}\text { God } \\
\text { games }\end{array}$ & $\begin{array}{l}\text { God Games have no preset win } \\
\text { conditions. Players are given a variety } \\
\text { of tools to work with and the player } \\
\text { chooses their own path. } \\
\text { COTS Examples: Civilization, Sim } \\
\text { City, Sim Life, Black \& White, Zeus, } \\
\text { The Settlers, Age of Empires }\end{array}$ & $\sqrt{ }$ & $\sqrt{ }$ & $\sqrt{ }$ & $\sqrt{ }$ & $\sqrt{ }$ & $\sqrt{ }$ & $\sqrt{ }$ & $\sqrt{ }$ & $\sqrt{ }$ & $\sqrt{ }$ & $\sqrt{ }$ \\
\hline $\begin{array}{l}\text { Educa- } \\
\text { tion } \\
\text { games }\end{array}$ & $\begin{array}{l}\text { The goal is to teach a specific body of } \\
\text { knowledge. Clear goals are set. } \\
\text { COTS examples: Oregon Trail, You } \\
\text { Don't Know Jack!, Emergency Room 2, } \\
\text { Bob the Builder }\end{array}$ & & & $\sqrt{ }$ & $\sqrt{ }$ & $\sqrt{ }$ & & & & $\sqrt{ }$ & $\sqrt{ }$ & $\sqrt{ }$ \\
\hline $\begin{array}{l}\text { Puzzle } \\
\text { games }\end{array}$ & $\begin{array}{l}\text { Puzzles presented on their own } \\
\text { without story or content action. } \\
\text { COTS examples: Tetris, Family Feud, } \\
\text { Wheel of Fortune, Austin Powers: } \\
\text { Operation Trivia, Assimilation, } \\
\text { Dilbert's Desktop Games, Chain } \\
\text { Reaction }\end{array}$ & & & & $\sqrt{ }$ & $\sqrt{ }$ & & & & & $\sqrt{ }$ & $\sqrt{ }$ \\
\hline Online & $\begin{array}{l}\text { Games from any genre can be } \\
\text { modified appropriately to play over } \\
\text { the Internet individually or with other } \\
\text { online gamers. } \\
\text { COTS examples: Pool \& Poker, to } \\
\text { Commandos 3: Destination Berlin, } \\
\text { Age of Wonders, Ultima Online, } \\
\text { EverQuest, Star Wars Galaxies, Quake, } \\
\text { Nation States, World of Warcraft, Final } \\
\text { Fantasy XI }\end{array}$ & & & & & & of g & & & & & \\
\hline
\end{tabular}

best organised groups rise to the top of the game. Activities performed during gaming sessions can be classified into four types: game playing and building; coordination and scheduling; support and advice; and social interaction. All these are important interpersonal communication skills for the workplace and life in general. Seay et al. (2004) discovered interesting patterns through interviews and surveys involving 1836 informants, with ages ranging from 12 to 68 . Table 2 summarises some of those findings that are of interest to this study. 
Table 2: Online gamer behaviour patterns

(adapted from Seay et al., 2004)

\begin{tabular}{|c|c|c|}
\hline \multicolumn{2}{|c|}{ Average time per week with preferred game } & 15-21 hours \\
\hline \multicolumn{2}{|c|}{ Percentage of gamers involved playing $>40$ per week } & $12 \%$ \\
\hline \multicolumn{2}{|c|}{$\begin{array}{l}\text { Percentage of gamers who communicate "outside" the } \\
\text { game with other gamers }\end{array}$} & $\begin{array}{l}69 \% \\
(28 \% \text { have none })\end{array}$ \\
\hline \multicolumn{2}{|c|}{$\begin{array}{l}\text { Most frequently used method of out of game } \\
\text { communication }\end{array}$} & $\begin{array}{l}\text { Forums } \\
\text { (message boards) }\end{array}$ \\
\hline \multirow{3}{*}{$\begin{array}{l}\text { Main activities for out of } \\
\text { game communication }\end{array}$} & coordination and scheduling & $57 \%$ \\
\hline & support and advice & $55 \%$ \\
\hline & social interaction & $53 \%$ \\
\hline
\end{tabular}

Educational value is defined as the change and positive experiences in learners, involving seamless movement to and fro between moments of surface and deep learning, cooperation with others, contributions to the dialogue, and feelings of self worth. This sense of educational value of instructional gaming has inspired the research in this project. In the words of renowned Atari game designer and author Chris Crawford (1982):

[Games are] the most ancient and time-hono[u]red vehicle for education. They are the original educational technology,... having received the approval of natural selection. In light of this, the question, 'Can games have educational value?' becomes absurd. It is not games but schools that are the newfangled notion, the untested fad, the violator of tradition. (pp. 16-17)

\section{Project overview and research methodology}

The methodology adopted in the overall project entails an action research (AR) case study in two cycles or stages.

Stage AR-1 was used to show "proof of concept" through a pilot study involving Swan View Senior High School teachers and students, and is the primary focus of this paper. The research in this stage followed a reflective pattern, leading to a revised plan, identified by a title and questions leading to further actions, observation and reflection in the next stage, as per the iterative Deakin model of the action research process (Kemmis \& McTaggart, 1998).

Further work in Stage AR-2 will see the project expand to more schools, as result of the findings in AR-1. AR-2 will also see the development of a curriculum plan and resources kit for the use of MMORPGs in high schools, with students and teaching resources and the Medieval Castle MMORPG online at a central, University maintained server. 


\section{Pilot study: Rochester Castle MMORPG}

The pilot study in Stage AR-1 of the project involved a total of 48 students in Year 8 and Year 9 (aged 13 to 15) English and Science classes taught by Diane Hobbs and Mark Weber at Swan View Senior High School, who engaged in MMORPG game design and game play to learn about 'Medieval Times'.

The Year 8 Society and Environment (S\&E) students "built" Rochester Castle (1087-1100 AD) in Kent, England in order to explore the outcomes of the unit "The Changing World" in an interactive way. For this purpose, a MOO (multi-user dungeon, object oriented) based collaborative virtual environment was used to host the MMORPG.

The aims and significance for all participants were novel. At the end of the study:

- Students had joined with another class curriculum to achieve joint learning outcomes by creating their own storyline, built and played in a MMORPG, and achieved new skills in learning collaboratively online;

- Teachers had developed new ICT skills and enhanced teaching practices by joining collaborative learning and games design theories, across subject boundaries;

- Researchers had investigated the effectiveness (educational value) the MMORPG scenario had on collaborative learning of two classes.

\section{Short history of Rochester Castle}

During the reign of Richard the Third, Prince John took over the throne of England, while King Richard was fighting the Crusades and then subsequently taken hostage. King John allowed allies to build a series of castles to strengthen his position. The Bishop of Rochester was one such ally and he petitioned King John for permission to build a castle. He needed to recruit a work force to build this castle along strict rules of the time, then staff it with soldiers to defend it against attackers. Rochester Castle was then attacked and was under siege in 1215 AD. It was the longest and best documented siege of the time (Cook, 2001).

\section{MMORPG game design}

A constructionist (Harel \& Papert, 1991; Kafai \& Resnick, 1996) approach was adopted to embed educational content into the design and development of the game itself, thereby increasing the relevance of the content to the students. A MOO lends itself particularly well to placing 
learners in the roles of producers or designers, rather than consumers, of games:

MOOs fulfill the other side of the promise of immersive worlds... EverQuest puts you in someone else's world, but in a MOO, the world was yours to help create. (Sugarbaker, 2003, para. 1)

The game design scenario had teachers Dianne Hobbs, Mark Weber and their students collaboratively re-construct the castle and characters of the time. Under the supervision of Leah Irving and their teachers, the students worked over six weeks in the computer lab and doing research and preparation for the game in the regular classroom. Although a majority of this activity was carried out on the school's premises during scheduled classroom hours, a number of students accessed the MOO from home in their own time, outside school hours.

Each student had a specific role to play based on the medieval society. Students were given a plan of the castle as a fortified manor house (keep), and they needed to access information to construct their own model of the castle within the game environment. For example, they researched the historical events, and planned and designed how to find access to the drawbridge, cellar and dungeon. Extension activities in the castle involved finding the treasure, or creating robots, and contributing to the future direction of the narrative.

Meanwhile, technical support and developmental (programming) assistance was provided by ISPG at Charles Sturt University, which was also responsible for advising on the theoretical foundations and framework for the research, as well as conducting data collection, analysis and reporting to facilitate the research.

\section{Multimedia and game architecture}

Rochester Castle MMORPG is based on an enCore Xpress enhanced MOO (MUD, object oriented). MOOs have their origins in multiplayer text adventure games (Bartle, 1990) called multi-user dungeons (MUDs), but contain object oriented features - a MOO is essentially a collection of objects. Locations (where players may gather), avatars (online representations of players) and things (balls, boxes, shoes or anything else) are all objects. Objects have attributes (properties) that describe their state (eg, appearance), as well as actions (called methods, or verbs) that they take in response to commands or messages. Some objects are containers and so can hold other objects. Locations, boxes and pockets are examples of containers. Objects are classified into a hierarchy with general characteristics inherited from higher level objects, and specialised attributes and methods distinguishing objects lower down the hierarchy. 
In a MOO, players have the appearance of being situated in an artificially constructed place (social space) that also contains those other players who are connected at the same time. MOO facilitates polysynchronous communications, that is, it allows for a hybrid communication model comprising both synchronous and asynchronous elements. For example, players can interact and chat in real time when they are simultaneously logged in to the MOO. In addition, their actions can impact and have a lasting effect on the state of the objects in the MOO, even after they have logged out - notes can be left on notice boards and signs erected which will allow messages to be left behind for other players; objects such as weapons and tools can be created, used, moved and otherwise manipulated; etc.

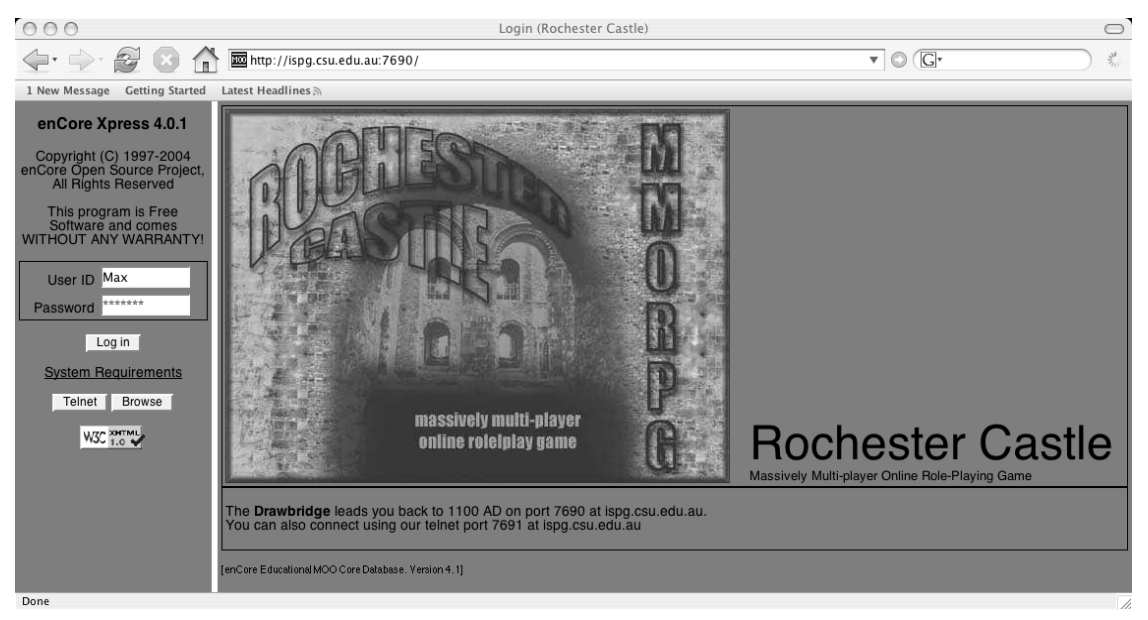

Figure 1: Rochester Castle MMORPG welcome screen designed by Leah Irving.

Users connect to a MOO server using a network client. Once connected, they control their avatar and other objects by typing commands. In addition to allowing text only mode connections using a Telnet client such as Pueblo, an enCore Xpress-enhanced MOO shows information about the current location, including contained objects and avatar icons, in one web browser frame, and dialogue in another frame by means of a Java applet called MOOtcan. A third frame houses a graphical toolbar providing convenient access to some of the most commonly used functions. While the natively text based nature of MOO lends itself particularly well to teaching and learning in domains such as languages and the humanities, the GUI and multimedia capabilities of enCore Xpress extend these benefits to other subject areas and help cater for different learning styles. Moreover, the fact that the interface is browser based promotes platform independence and interoperability with other Internet technologies. 
More information on the use of MOOs in education may be found in the work of Haynes \& Holmevik (2000). Rochester Castle MMORPG is hosted on the ISPG server at CSU (see Rochester Castle MMORPG, 2004). The system is run entirely using open source software: enCore Xpress 4.0 .1 (see Holmevik \& Haynes, 2004) under the FreeBSD operating system. The welcome screen appears in Figure 1.

\section{MMORPG game topology}

In the castle, the curtain wall features as the great corridor, from which all other rooms in the castle come off. The central hall is where life takes place, and the big grassy area (Figure 2) is called the common. MUD maps and layout diagrams are used to show gamers how to move throughout the castle and the grassy area and its surroundings.

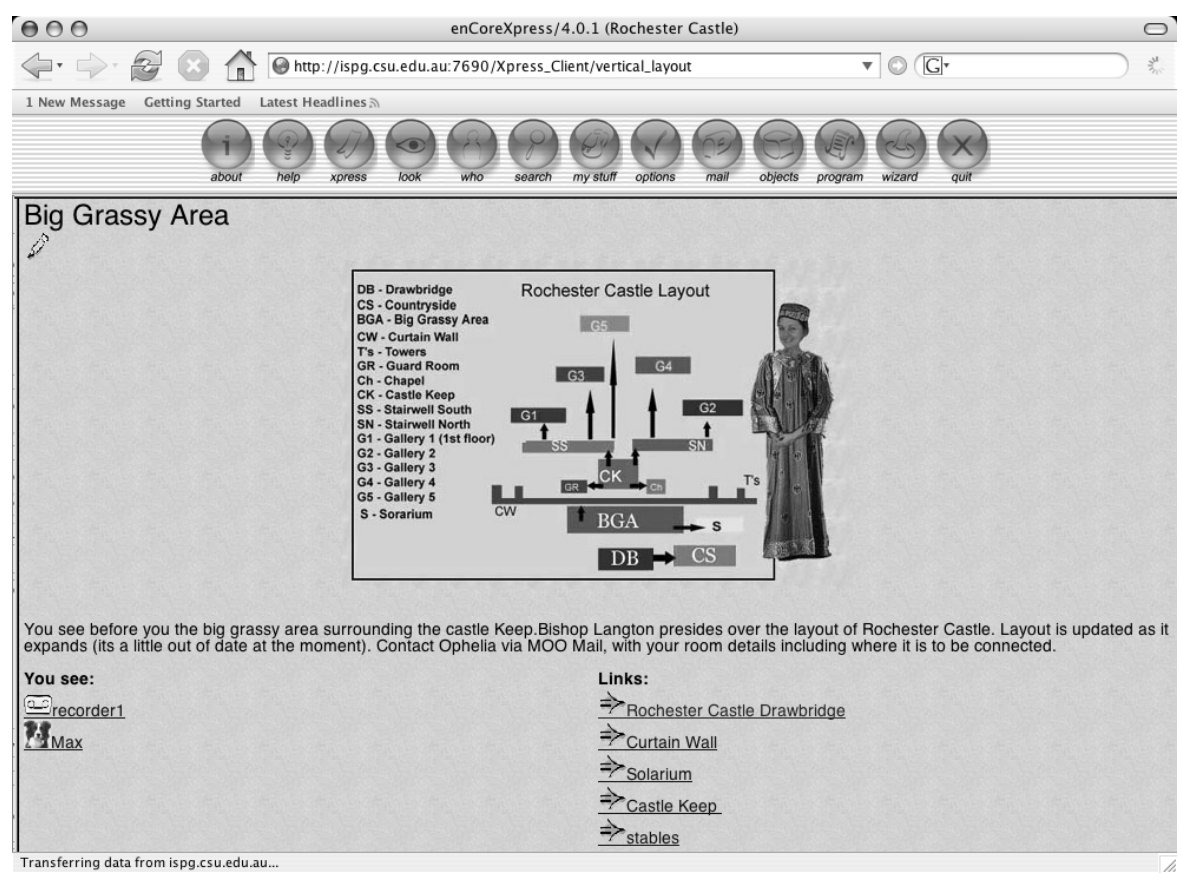

Figure 2: Rochester Castle layout and navigation map as seen from the grassy area.

\section{Avatar basics and customisation}

Each MOO avatar has a class or level. At the bottom are temporary avatars called guests who can only move around and chat to other avatars. A player has a more permanent identity, but can still only move and chat. A builder 
can create new objects (except avatars) and give them attributes such as a description. A programmer can create new behaviours or actions (verbs) that can be applied to objects. Verbs are written in the MOO programming language. Wizards can create and control other avatars and change attributes such as location, password or quota. They can gag, disconnect or even recycle avatars. The Arch Wizard at the top has ultimate power and responsibility.

It takes about ten minutes to learn to be a guest: to read location descriptions, move to other locations and chat to other participants. Most people who can type take to it very easily. Budding writers like to be builders and people who like logic, syntax and semantics can learn to be programmers. Good leadership skills are required for wizards.

The MOO allows players to build and customise their own unique avatar, including textual descriptions and multimedia representations that provide an online image and identity for the character. As applied to Rochester Castle MMORPG, not only does this encourage deep investment from students, it also challenges them to exercise their creativity while maintaining a level of historical accuracy.

\section{MMORPG game play}

The game started with the Archbishop of Rochester petitioning King John for a Cantenation. This was granted and the Bishop had to recruit his building force. The guilds involved were Stonemasons, Blacksmiths, Farmers, etc, and student groups took these on as allocated by ballot. Students were allowed to trade their guilds at the start of the game. Students were rewarded for participating in the game by acquiring barter tokens and gold. Any disputes were settled first by the Bishop of Rochdale or in the extreme by King John. Daily law enforcement was carried out by the Bailiff.

The castle was built by programmers creating rooms in the MOO. To build anything, they first needed to get permission from the Archbishop of Rochester (a wizard) to be allocated permission as a builder (or programmer). The students that were part of the attacking force had to research the engines of war for medieval times and needed to organise themselves into teams, then attack and lay siege to the castle.

\section{Development ideas for Rochester Castle MMORPG}

The programmable nature of MOO makes it ideal for the development of a MMORPG. The fact that it is object oriented makes it extensible. Capable players (programmers and wizards) can add to the underlying design by 
writing their own code in the scripting language provided. The MOO server provides a framework for basic functionality such as interfacing with the network, but all the real behaviours of objects are programmed in the scripting language and are part of the object oriented MOO database.

\section{"Key" object in place of guard "bot"}

Developing a Turing robot to act as a guard on the castle drawbridge posed some challenges for programmer, Allan Bytheway. The idea was that the "bot" (affectionately named Rod) would interact with the students and challenge them to provide a password. This password, if correct, then allowed them entrance to the castle. If they did not have the correct password they would be directed to move to the "field" surrounding the castle. The speech patterns to be used by the "bot", like other characters, were to be based on Ye Olde English. This raised some security issues, so the idea of using a "key" was developed.

The "key" was based on a "generic thing" object and a "turn" verb was written which moved the players to the "Big Grassy Area" inside the walls of the castle that surrounded the castle keep. The "key" was located in the "Rochester Castle Drawbridge" room, which was the default login position (home room) for all players. A list of players authorised to use the "key" was coded into a property of the "key". If an unauthorised player used the key, he/ she was told to go to the surrounding field.

The code for "turn" verb of the "key" object appears below. Note that \#170 is the object number of the "Big Grassy Area", while \#173 refers to the surrounding field.

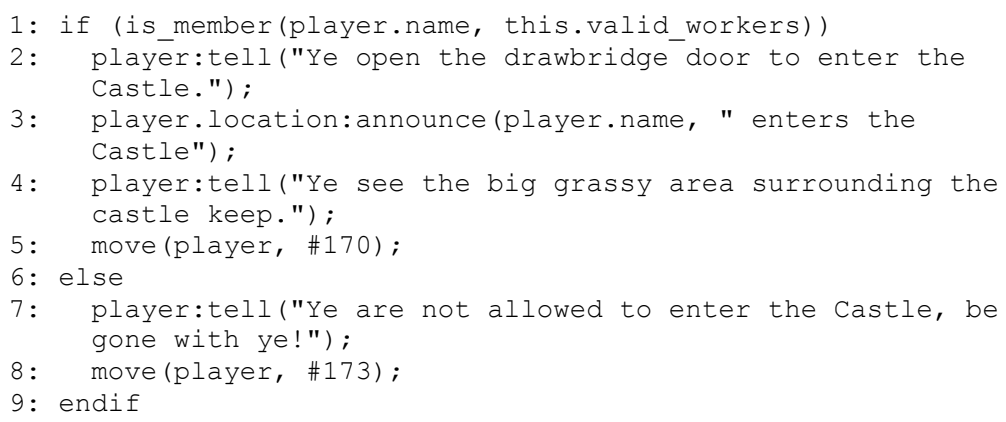

\section{"Stair" object to move players within the castle}

The real Rochester Castle had only a north stairwell and a south stairwell which lead to six different galley levels. To simulate moving between the six levels of the castle, a separate "stair" object was created which moved 
players to each of the other levels. This required the writing of a verb to transport players to the appropriate location. Two versions were written, a "climb" verb and a "descend" verb, to be used as appropriate. The code for the verb to be used for each stair object is based on the following examples and was modified to suit each location.

The code for the "climb" verb of the "stair" object is as follows:

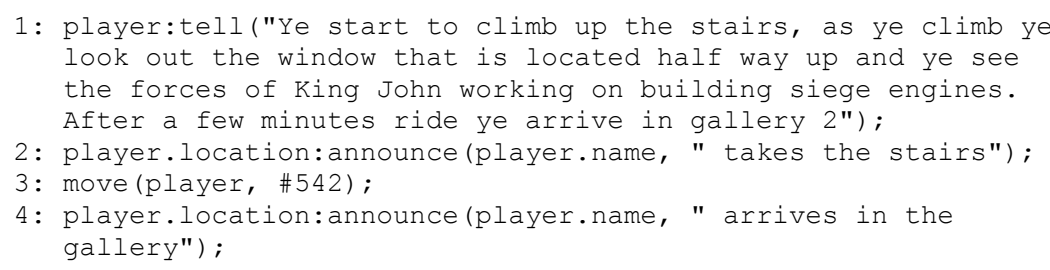

In the above code segment, \#542 is the object number of the destination room.

The code for the "descend" verb of the 'stair' object is shown below (once again, \#697 is the destination room):

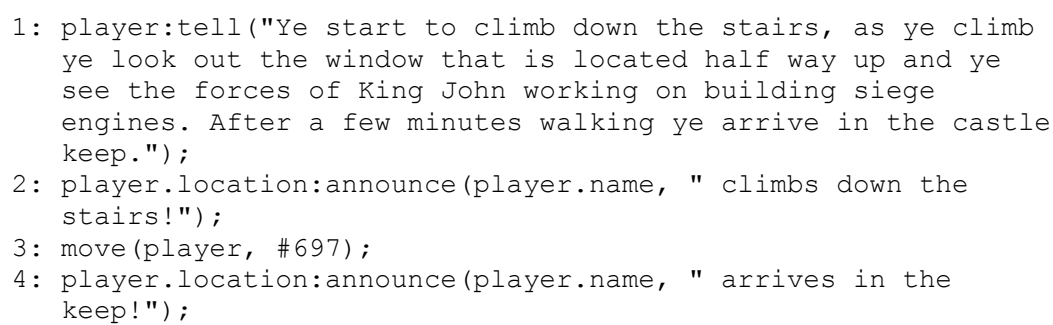

\section{Combat during the game}

To address the issue of simulating the fighting required for the game it was suggested that players "page" each other with carefully crafted, aggressive but appropriate messages.

The game required the foundations of the castle to be breached by the players laying siege to the castle. To accomplish this they burnt pig fat in tunnels dug beneath the castle foundations. To simulate this situation, a "foundation" object (based on a "generic thing" object) was created containing a "crumble" verb. This object was located in a room object called "tunnel" linked to the "Countryside". This verb moved the player using it inside the castle walls.

The code for the "crumble" verb of the "foundation" object is as follows: 
1: player:tell("Ye see that the pig fat fire has burnt the foundations and it starts to crumble, ye then are able to enter the castle");

2: player.location:announce (player.name, " moves through the hole in the foundation");

3: move (player, \#640);

4: player.location:announce (player.name, " arrives in the east tower");

\section{Analysis of online gamer activity and usage patterns}

\section{Analysis tools and techniques}

An analysis of gaming participation was performed by applying UNIX commands, shell scripts and Smalltalk programs to the MOO logs. For example, the grep UNIX command was used by the researchers to perform initial analysis and preparation of the log files for analysis. Grep isolates lines in text files such as logs that match a specified pattern. One useful application of this is that all occurrences of a particular player's dialogue contributions can be extracted into a single block for further processing and detailed examination.

MOO logs consist of lines in the format date-time: COMMAND: message, except for the first line which gives the starting day, date (including year and time zone) and time.

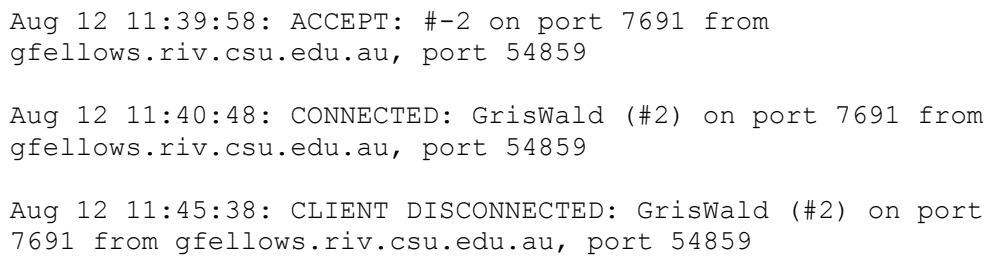

The above three lines show a client program connecting from the host gfellows.riv.csu.edu.au (ACCEPT), logging in with a player name and password (CONNECTED) then logging out and disconnecting (CLIENT DISCONNECTED) about six and a half minutes later. The player name is "Griswald" and the player's object number is \#2. Players may rename their player but cannot change the initial object number.

Several Smalltalk (Why Smalltalk: Supporting the Smalltalk Community, 2004) programs were written to convert the 12 megabyte Rochester MOO log file into various forms for spreadsheet analysis. Squeak Smalltalk was chosen because of the range of graphical displays possible. It is intended to use Information Space (Tabone, 2004) to help visualise the data better than a 
spreadsheet chart. Statistics such as duration of player sessions can be easily extracted from the MOO $\log$ file, as has been done for the analysis presented in this paper.

\section{Analysis of results and findings}

The analysis showed that 53 online gamers (including 48 students, 2 teachers and 3 research team members) used Rochester Castle MMORPG for a total of approximately 223 gamer hours. Table 3 below records the general participation statistics for the game over all sessions. Fig. 3 reveals the pattern of time spent playing the game by the gamers.

Table 3: Student participation statistics for Rochester Castle MMORPG $(\mathrm{n}=53)$

\begin{tabular}{|l|c|}
\hline & Gaming hours \\
\hline Highest participation & 20.55 \\
\hline Lowest participation & $0.1(5.7 \mathrm{~min})$ \\
\hline Average number of hours & 5.62 \\
\hline
\end{tabular}

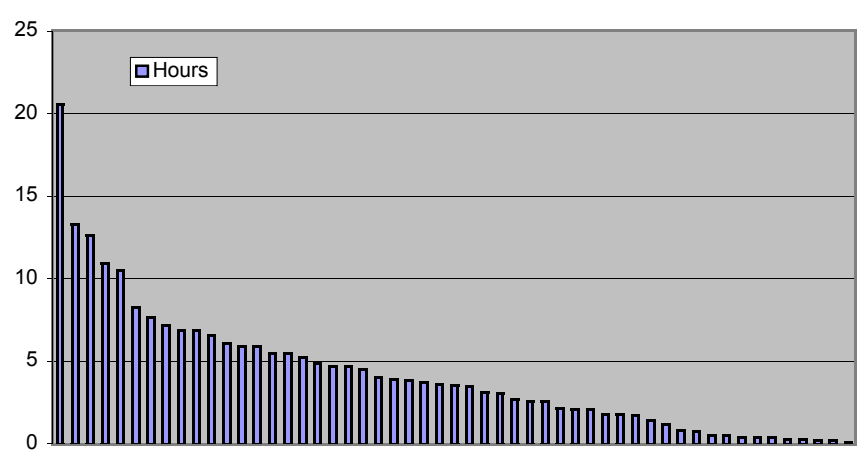

Figure 3: Rank order of the time spent (hours) gaming by all students at Rochester castle

The student player named "Charles the Squire" had almost double the average playing time of the next 5 highest in the list of top 25 gamers by time spent at Rochester Castle (Table 4). The gradient of the curve gets significantly steeper after the player called "Simon the Steward". An ethnographic study of the Rochester Castle community (Eustace, 1998) will make an interesting follow up investigation.

Table 5 summarises the research team members' and teachers' use of the MOO. The average time spent by the teachers supporting the game (about 9 hours) is about double the average time spent by students. This appears to be typical of normal lesson preparation time. The analysis suggests that 
instructional gaming with Rochester Castle and similar interactive MMORPGs is about the same workload as conventional teaching where each hour in the classroom is matched by an hour of preparation beforehand. It must be recognised, however, that the real total of hours spent by the classroom teacher may be larger than expected when participating in a research and development activity; this issue warrants further investigation. Additionally, teachers must be willing to spend several hours developing competency with the technology and instructional gaming teaching skills, before attempting classroom use. It is envisaged that the teachers would then spend the usual amount of time on lesson planning and development, for each use of the game.

Table 4: List of top 25 gamers by hours spent

\begin{tabular}{|l|c|}
\hline Character & Hours \\
\hline Charles the Squire & 20.55 \\
\hline Sir Eramus & 13.27 \\
\hline Reginald the Squire & 12.60 \\
\hline Claramunda & 10.95 \\
\hline Andrew & 10.46 \\
\hline Simon the Steward & 8.27 \\
\hline Oliver the Don & 7.66 \\
\hline Ralph the Squire & 7.17 \\
\hline Bryan the Squire & 6.88 \\
\hline Valentine the Cotter & 6.83 \\
\hline Agnes & 6.53 \\
\hline William the Squire & 6.07 \\
\hline Warren & 5.88 \\
\hline Isabelle & 5.88 \\
\hline Walter de Hugh & 5.48 \\
\hline Griffin & 5.47 \\
\hline Zacheus & 5.25 \\
\hline Apothecary & 4.91 \\
\hline Sir Bartholemew & 4.71 \\
\hline Lord Nicholas & 4.68 \\
\hline Geoffrey the Bailiff & 4.50 \\
\hline Lord Richard & 4.01 \\
\hline Maxwell & 3.87 \\
\hline Sir James & 3.84 \\
\hline Avis & 3.73 \\
\hline
\end{tabular}

Table 5: Summary of non-student gamers' participation

\begin{tabular}{|l|l|c|c|}
\hline Participant type & Names & Hours & Sessions \\
\hline Research team & Ophelia & 87.87 & 71 \\
\cline { 2 - 4 } & Castledog & 25.86 & 44 \\
\cline { 2 - 4 } & Bailiff Bill & 7.78 & 33 \\
\cline { 2 - 4 } & Total & 121.51 & \\
\hline \multirow{5}{*}{ SVSHS teachers } & Langton & 10.33 & 20 \\
\cline { 2 - 4 } & King John & 8.40 & 26 \\
\cline { 2 - 4 } & Total & 18.74 & \\
\hline
\end{tabular}


Over the period 12 August 2004 to 4 October 2004, 383 sessions were held at Rochester Castle MMORPG. A session may be defined as the contiguous period during which one or more players remain connected to the MOO. It should be noted that disconnection may occur intentionally when a player logs off from the system, or due to other reasons such as technical difficulties (eg, network connection faults).

Of the total of 223 hours of session time for data collection, 102.9 hours (46.16\% of all sessions) involved multiple players interacting with the MMORPG. The 102.9 hours were recorded for 63 of the 383 sessions or $16.45 \%$ of all sessions, while the average time per multiplayer session was 1.63 hours. The number of sessions with 10 or more players was 16 and the average number of players per multi-player session was 6.86 .

Figure 4 records the peak game playing attendance for the period of the trial with a duration peak of 6 players for 7 hours and 6 minutes on 31 August 2004, and a players per session peak of 29 players for 58 minutes on 28 September 2004. The 3-D chart in Figure 5 compares the same pattern of statistical data for session duration figures (short buildings) with the number of multiple players per session (taller buildings at rear).

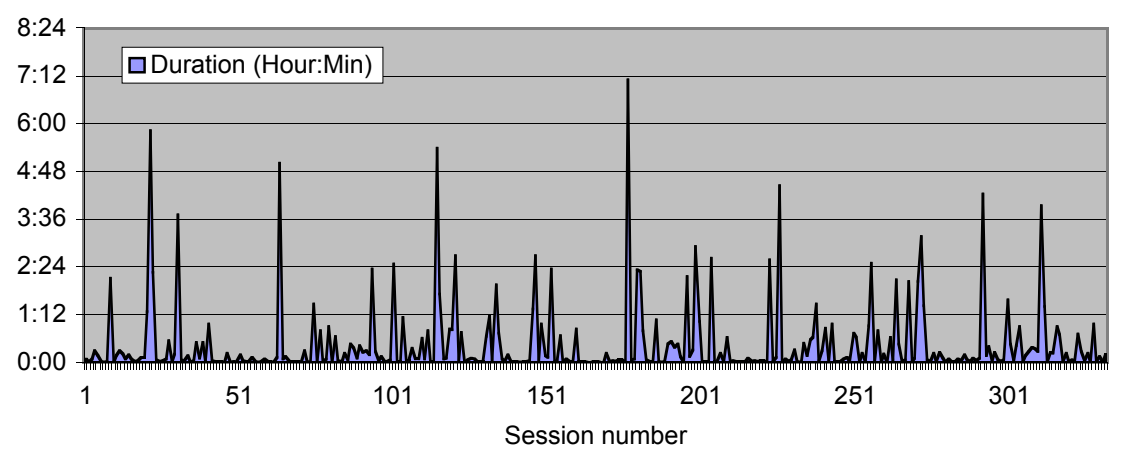

Figure 4: Duration of each session (1 to 383) at Rochester Castle over the period of the pilot study.

\section{Conclusion}

The development, testing and investigation of the use of a massively multiplayer online role playing game (MMORPG) to enhance teaching and learning in the English and Science domains has been a challenging and rewarding experience for the research team, staff and students. Collaborative learning was facilitated both during the design of the game, as the students, teachers and researchers worked together to plan and implement the game, as well as in the game play, in which the gamers formed guilds to undertake collaborative role play and problem solving. 


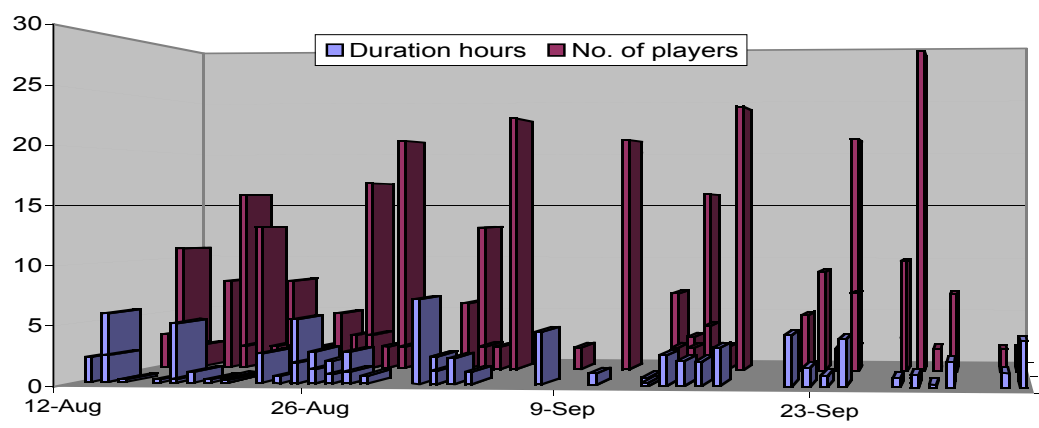

Figure 5: Comparison of session duration with number of players per session.

In the context of the overarching project, the findings from the AR-1 cycle pose the research questions for the AR-2 cycle. Role play, character engagement and the generative nature of discovery were considered important elements of the MMORPG game play and will be the subject of more in depth exploration in a subsequent article. Additionally, in AR-2, the authors plan to conduct further data analysis to confirm the educational value of instructional gaming within an enCore MOO based MMORPG. It is anticipated that this will require both qualitative and quantitative analysis of game playing and log files, as well as teacher feedback and structured interview data. Specifically, this further analysis will examine:

1. the number of sessions gaming outside school hours by the students, as an indication of motivation and reward;

2. the different types of activity done in each session such as: game playing and building, coordination and scheduling, support and advice, social interaction;

3. the ease of learning and use of ICT and enCore / MOO training resources for school staff, so that this form of instructional gaming can be part of professional practice.

Expressions of interest to participate in the project have been received by several other high schools throughout the country, who will explore their local histories within the MOO. The authors plan to support truly "massive" numbers of students from these schools building a history of Australia from a local perspective. The history of indigenous Australia will be a strong part of this. The idea is similar in concept to the games design of Rochester Castle MMORPG - it will entail having students build and role play some significant event, possibly looking at various scenarios and 
their outcomes. Additionally, students will be able to visit each others' historical sections to learn from them with coordinated synchronous sessions to build social networks and perhaps even carry out collaborative role play. To handle this level of complexity, a very thorough navigation plan will be necessary to prevent the different sections from becoming overly fragmented and lost.

The ISPG researchers and developers are in the process of developing a CD "toolkit" and supporting website which will contain curriculum resources, HOWTOs, and solutions for overcoming firewall access restrictions in place in many schools (whereby connections must go through the default HTTP port 80). A Wiki will also be hosted on the ISPG server to support interaction of players outside the game environment.

Finally, further technical development is underway. This will see the introduction of an XML User Interface Language (XUL) based (The Mozilla Organization, 2005b) interface for the MOO, using Mozilla Firefox (The Mozilla Organization, 2005a) as the recommended web browser. Also, MOOs are currently interoperable with email servers, with messages able to be passed seamlessly between the two systems. ISPG plans to extend enCore Xpress so that it supports integration with web logs (blogs) as well as instant messaging (IM) clients such as AOL instant messenger (AIM), ICQ, MSN messenger and Yahoo! messenger, given the popularity of these technologies amongst youths. This will open up new possibilities in the way of allowing different MMORPG actions to be carried out asynchronously and facilitating better communication, networking and support between players inside and outside the MMORPG.

The development of resources and the research project itself are expected to be completed in mid-2005 and the end of 2005 respectively. It is hoped they will contribute to promoting the uptake of instructional gaming in high schools both in Australia and overseas, as well as simplifying the integration of MMORPG based collaborative teaching and learning into contemporary secondary curricula.

\section{Acknowledgements}

The authors wish to thank the Principal, staff and students of Swan View Senior High School, Perth, Western Australia, in particular Diane Hobbs and Mark Weber, as well as the Research Into Professional Practice, Learning and Education (RIPPLE) research centre at Charles Sturt University. 


\section{References}

Aldrich, C. (2004). Simulations and the Future of Learning: An Innovative (and Perhaps Revolutionary) Approach to e-Learning. San Francisco: Pfeiffer.

Australian Bureau of Statistics (2003). Children's Participation in Cultural and Leisure Activities, Australia, (Catalogue 4901.0). Canberra: ABS. [viewed 1 Apr 2005, verified 29 Apr 2005]

http: / / www.abs.gov.au/Ausstats / abs@.nsf/Lookup/0B14D86E14A1215ECA2 569D70080031C

Bartle, R. (1990). Interactive multi-user computer games. [viewed 18 Nov 2004, verified 29 Apr 2005] http: / / mirrors.ccs.neu.edu/MOO/papers/mudreport.txt

Bonk, C.J. \& Wisher, R.A. (2000). Applying collaborative and e-learning tools to military distance learning: A research framework. Alexandria, VA: U.S. Army Research Institute for the Behavioral and Social Sciences [viewed 15 Mar 2005, verified 29 Apr 2005] http: / / www.publicationshare.com/docs/Dist.Learn(Wisher).pdf

Bruner, J. (1986). Actual minds, possible worlds. Cambridge, MA: Harvard University Press.

Bruner, J. (1990). Acts of meaning. Cambridge, MA: Harvard University Press.

Bruner, J. (1996). The culture of education. Cambridge, MA: Harvard University Press.

Butterfield, S. (2003). Thinking outside the MUD: Ludicorp CEO Stewart Butterfield on the Game Neverending (Interview by M. Sugarbaker). [viewed 8 Apr 2005, verified 29 Apr 2005] http:/ / www.mindjack.com/feature/gne.html

Cook M.W. (2001). Rochester Castle. [viewed 18 Nov 2004, verified 29 Apr 2005] http: / / www.castles-abbeys.co.uk/ Rochester-Castle.html

Crawford, C. (1982). The art of computer game design (Electronic Version). [viewed 20 Mar 2005, verified 29 Apr 2005]

http: / / www.mindsim.com/MindSim/Corporate/artCGD.pdf

Cunningham, D. J. (1995). Time after time. In W. Spinks (Ed), Semiotics 95 (pp.263269). New York: Lang Publishing.

Dewey, J. (1929). The sources of a science of education. New York: Liveright.

Eustace, K. (1998). Ethnographic study of a virtual learning community, Internet Research: Electronic Networking Applications and Policy, 8(1), 83-84.

Game Developers' Association of Australia. (2003). [viewed 29 Apr 2005] http: / / www.gdaa.asn.au/

Gee, J. P. (2003). What Video Games Have to Teach Us About Learning and Literacy. New York: Palgrave Macmillan.

Gee, J. P. (2004). Learning by design: Games as learning machines. Paper presented at the Game Developers Conference, San Jose, CA, March 22-26. [viewed 8 Mar 2005, verified 29 Apr 2005]

http:/ / www.gamasutra.com/gdc2004/features/20040324/gee_01.shtml 
Gikas, J. \& Van Eck, R. (2004). Integrating video games in the classroom: Where to begin? Paper presented at the National Learning Infrastructure Initiative 2004 Annual Meeting, San Diego, CA, January 25-27. [viewed 14 Apr 2004, verified 29 Apr 2005] http: / / www.educause.edu/ir/library/pdf/NLI0431a.pdf

Harel, L. \& Papert, S. (Eds) (1991). Constructionism. Norwood, NJ: Ablex.

Haynes, C. \& Holmevik, J. R. (2004). MOOniversity: A student's guide to online learning environments. Needham Height, MA: Allyn \& Bacon.

Hiltz, S. R. (1998). Collaborative learning in asynchronous learning environments: Building learning communities. Paper presented at WebNet 98, Orlando, FL, November 7-12. [viewed 15 Mar 2005, verified 29 Apr 2005] http:/ / eies.njit.edu / hiltz/collaborative_learning_in_asynch.htm

Holmevik, J. R. \& Haynes, C. (2004). enCore Open Source MOO Project [viewed 29 Mar 2005, verified 29 Apr 2005] http:/ / lingua.utdallas.edu/encore/

Irving, L. (2004). The siege of Rochester Castle: What do MUVEs in the curriculum have to offer the social and emotional development of young people, particularly boys? Unpublished master's thesis, Deakin University, Burwood, Vic.

Johnson, D. W. \& Johnson, R. T. (1999). Learning together and alone: Cooperative, competitive, and individualistic learning. 5th ed. Boston: Allyn \& Bacon.

Johnson, D. W., Johnson, R. T. \& Stanne, M. B. (2002). Cooperative learning methods: A meta-analysis. [viewed 23 Nov 2004, verified 29 Apr 2005] http: / / www.cooperation.org/pages/cl-methods.html

Kafai, Y. \& Resnick, M. (Eds) (1996). Constructionism in practice: Designing, thinking and learning in a digital world. Mahwah, NJ: Erlbaum.

Kemmis, S. \& McTaggart, R. (1988). The Action Research Planner. 3rd ed. Geelong, Vic: Deakin University.

Lepper, M. R. \& Malone, T. W. (1987). Intrinsic motivation and instructional effectiveness in computer-based education. In R. E. Snow \& M. J. Farr (Eds), Aptitude, learning and instruction, vol. 3: Cognitive and affective process analysis (pp.253-286). Hillsdale, NJ: Erlbaum.

Palloff, R. \& Pratt K. (1999). Building learning communities in cyberspace. San Francisco: Jossey-Bass.

Papert, S. (1998), Does easy do it? Children, games, and learning. Game Developer, $5(6), 88$.

Piaget, J. (1951). Play, dreams and imitation in childhood. London: Routledge \& Kegan Paul.

Prensky, M. (2001). Digital Game-Based Learning. New York: McGraw-Hill.

Project Massive (2004). [viewed 22 Nov 2004, verified 29 Apr 2005] http: / / www.projectmassive.com/

Rieber, L.P. (1996). Seriously considering play: Designing interactive learning environments based on the blending of microworlds, simulations, and games. Educational Technology Research E Development, 44(2), 43-58.

Rochester Castle MMORPG (2004). [viewed 10 Nov 2004, verified 29 Apr 2005] http: / / ispg.csu.edu.au:7690/ 
Rovai, A. (2002). Development of an instrument to measure classroom community. The Internet and Higher Education, 5, 197-211.

Seay, A. F., Jerome, W. J., Lee, K. S. \& Kraut, R. E. (2004). Project Massive: A study of online gaming communities. In E. Dykstra-Erickson \& M. Tscheligi (Eds), Proceedings of the 2004 Conference on Human Factors in Computing Systems (pp.1421-1424). New York: ACM.

Sugarbaker, M. (2003). Thinking outside the MUD: Ludicorp CEO Stewart Butterfield on the Game Neverending. [viewed 8 Apr 2005, verified 29 Apr 2005] http:/ / www.mindjack.com/feature/gne.html

Tabone, B. (2004). Information Space. [viewed 7 Oct 2004, verified 29 Apr 2005] http:/ / www.softcentral.com/informationspace

The Mozilla Organization (2005). Firefox - Rediscover the Web. [viewed 14 Apr 2005, verified 29 Apr 2005] http: / / www.mozilla.org/products/ firefox

The Mozilla Organization (2005). XML User Interface Language (XUL) Project. [viewed 14 Apr 2005, verified 29 Apr 2005] http: / / www.mozilla.org/projects / xul

Thurman, R.A. (1993). Instructional simulation from a cognitive psychology viewpoint. Educational Technology Research \& Development, 41(4), 75-89.

Van Eck, R. N. (2000). The effect of advisement and competition on transfer, advisor use, and attitude toward mathematics using a computer-based simulation game (Doctoral dissertation, University of South Alabama, 2000). Dissertation Abstracts International, 61(1), 146A.

Vygotsky, L.S. (1978). Mind in society: The development of higher psychological processes. Cambridge, MA: Harvard University Press.

Why Smalltalk: Supporting the Smalltalk Community (2004). [viewed 7 Oct 2004, verified 29 Apr 2005] http:/ / www.whysmalltalk.com/

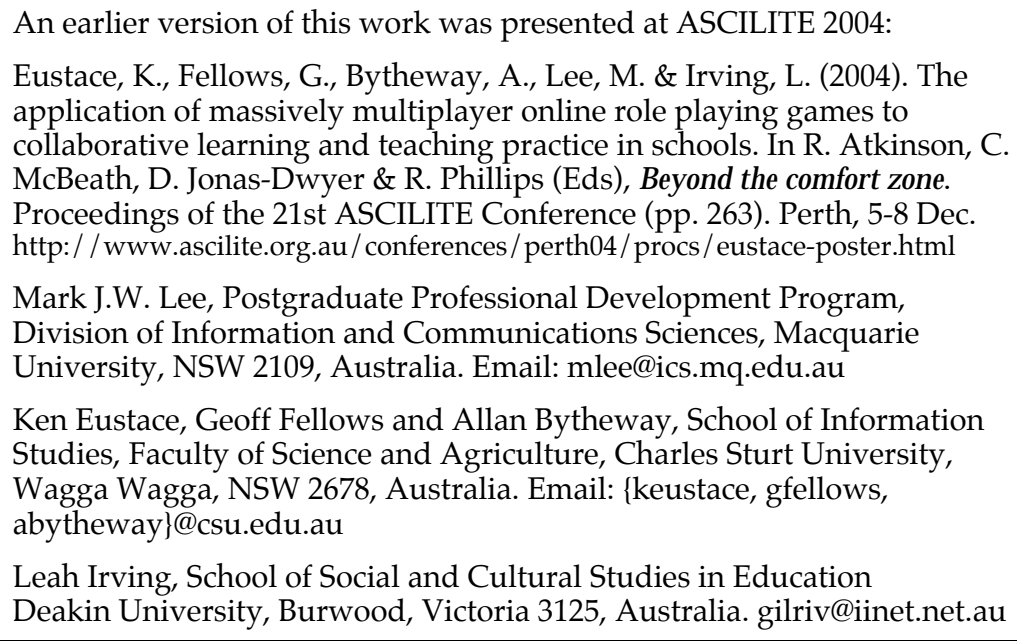

